\title{
Definitions of Meaningful Work for Generation X and Millennial Cuspers
}

\author{
Beverly Van Hyatt \\ School of Business and Technology, Capella University, Minneapolis, USA
}

\section{Email address:}

Bvhy195@gmail.com

\section{To cite this article:}

Beverly Van Hyatt. Definitions of Meaningful Work for Generation X and Millennial Cuspers. Journal of Human Resource Management. Vol. 9, No. 1, 2021, pp. 1-14. doi: 10.11648/j.jhrm.20210901.11

Received: December 3, 2020; Accepted: December 10, 2020; Published: January 12, 2021

\begin{abstract}
Objective: In today's multigenerational workforce, organizational leaders continuously seek methods to retain valued employees. Employees who perceive their work-related values are in alignment with their employer is central to intentions to quit. In this study, generational differences in definitions of meaningful work among the Gen $\mathrm{X}$ and Millennials cusp cohorts and between genders were investigated. Method: A quantitative nonexperimental survey approach was applied using self-reported measures of the Comprehensive Meaningful Work Scale (CMWS). Two hundred eleven US-based employees in various professional, semi-professional, and non-professional occupations provided their perceptions of meaningful work. An ANOVA was used as the method of analysis. Results: The results indicated no significant differences in definitions of meaningful work between individuals of Gen X and Millennials on the cusp of their generation. Furthermore, there were no significant differences in definitions of meaningful work between gender of Gen X and Millennial cusp cohorts. The results revealed similarities in definitions of meaningful work among Gen X and Millennial Cuspers and between genders. Conclusions: Employees of all generations pursue meaningful work. Recommendations include the use of qualitative methodological approaches, longitudinal studies, and multiple data points to explore intergenerational differences to analyze how generations effect change in the workplace.
\end{abstract}

Keywords: Meaningful Work, Generational Differences, Generation X, Millennials, Cusp Cohorts, ANOVA

\section{Introduction}

With more older Americans working than in previous decades, organizational leaders and researchers are focusing on the range of generational differences in today's workplace and how their employees define meaningful work [1]. Indeed, changes in work landscapes are causing employers to focus on more than just financial rewards and incentives; instead, they consider establishing business environments and policies that enable employees to be accountable for their growth and development. People spend the better part of their day at work, ideally for reasons beyond just earning a paycheck [2], but rather to promote personal fulfillment and meaningfulness. Meaningful work is linked to employee well-being, self-reflection, a sense of harmony, and satisfaction $[1,4]$. For some, meaningful work is associated with a life purpose or calling and a feeling of self-reflection [4].

Scholars have long given the proverbial nod to organizations that have aligned their recruitment, recognition, and management strategies with their employees experiencing meaningfulness at work. Values linked to meaningful work can contribute to an employee's professional needs and how they accomplish them.

The debate as to what constitutes meaningful work is ongoing, with many employers concerned with how to manage subordinates' productivity and goals while at the same time providing meaning and fulfillment for all workers within a multi-generational work environment. Researchers of organizational science are becoming increasingly interested in variations of generational differences and employers' obligation to provide a work environment wherein an employee can develop and pursue personal ambitions [6-7].

For this report, generational differences refer to disparities in work-related values, attitudes, personalities, leadership styles, and employment decisions [3]. As of 2019, five generations are represented in the US workforce to varying degrees: Traditionalists (1922-1945), Baby Boomers 
(1946-1964), Generation X or GenXers (1965-1981), Millennials or Generation Y (1982-1999), and Generation Z (2000-). They are just entering the workforce [8, 3]. Among these, GenXers and Millennials signify the workforce's predominant generation, particularly now that more Baby Boomers are retiring [9].

Within these generations are individuals born on each generation's cusp, who are known as tweeners [10]. Specifically, tweeners are born during the last three to five years of a given generation $[11,12]$.

There is an emerging interest in the values and characteristics of those born on the cusp of generational cohorts. Researchers seek to answer questions such as why individuals identify with generational groups, whether there is homogeneity within the cohorts, and if the diversity within and between generational sub-groups is sufficiently significant to respond to the legitimacy of generations as a workplace phenomenon. Empirical contributions have supported generational differences and associations of personality, values, and beliefs of those born beyond the first or last five years of a generation-i.e., within the core of a generation. However, it would be interesting to examine whether perceptions are different for those within the cusp of the generation.

Discussions of generational differences continue to inform organizational behavior, human resource practices, business ethics, corporate social responsibility, and other internal work processes in the disciplines of philosophy, psychology, and organizational sciences [3]. Business leaders seek to understand the perceptions of employees regarding meaningful work and how they can structure the business milieu to support and provide a work environment that contributes to meaningfulness so that individuals can develop and pursue aspirations that contribute to their life's purpose $[3,4]$.

Subjective experiences within the work environment have come to define meaningful work in various ways-first as an existential necessity to fulfill basic human needs $[3,4,14,6]$. From a Kantian perspective, however, meaningful work characterizes labor that is freely chosen, facilitates autonomy and independence, promotes advancement, provides growth opportunities, and pays equitably [7].

Previous studies have measured differences and commonalities across generations in the workplace but rarely considered individualistic dispositions and perceptions beyond those who are a part of the collective age group [15]. Although age demarcations that define generational birth years are not entirely consistent across the literature, this report uses the work of Twenge, Campbell, Hoffman, and Lance [60]. This study investigated differences in definitions of meaningful work among the cusp cohort by using statistical analysis to explain significant differences among cusp cohorts regarding how GenXers and Millennials define meaningful work. This study also includes a review of generational theory's theoretical perspectives to determine notable differences in values and beliefs of meaningful work. Results from this investigation could help fill a gap in the field of organizational management and human resources by highlighting sub-groups within generations, thereby contributing to the body of knowledge on generations and the changing role of work-related values.

Meaningful work is linked to a range of desirable outcomes for employees and organizations, such as job satisfaction, motivation, commitment, performance, work engagement [17], supportive internal relationships, enhanced customer service, and other workplace behaviors $[1,17,18]$. The study of generations and meaningful work within the management discipline is relevant for both researchers and practitioners. For example, employers who discern and act upon accepted differences among generations may be better equipped to promote workplace coherence and productivity [8]. By revealing and discussing differences in individuals' perceptions across generations, this study's findings are expected to provide organizational leaders with the tools to develop meaningful work practices that can be implemented in developmental and retention strategies.

\section{Literature Review}

\subsection{Generational Differences}

Generational differences represent age-based divisions and variations in mindset, personality, values, and beliefs. Researchers have been examining commonalities among individuals who share the same age range and are exposed to similar era-specific historical events and experiences for quite some time $[10,3]$.

There is much debate regarding the validity of generational differences, with scholars questioning whether generational differences exist [20]. For instance, some question the utility of using intuitive beliefs and generations' labels to overgeneralize individual differences to an entire group [21]. Still, others have purported that the difficulty in distinguishing generational characteristics as a matter of value can be problematic, mostly because of the age confound [13, 22]. Of interest for this study is whether people born within a cusp cohort will behave markedly different from others within the generations [19]. The following section encapsulates the salient differences between the three generations represented in today's workforce.

Baby Boomers: Comprising a large segment of the population, Baby Boomers significantly influences society [11]. Historical events specific to Boomers include the Vietnam War, the Civil Rights Movement, Watergate, Woodstock, and the Kennedy and King assassinations [52, 61]. Research shows that Baby Boomers value self-enhancement, achievement, and power; they perceive work as an extension of themselves [28, 29].

Generation X: GenXers were born during economic uncertainty, inflation, high unemployment, and corporate downsizing. GenXers are members of the "latchkey kid" generation due to soaring divorce rates during their growing-up years [29]. GenXers were the first to be introduced to widely available technology such as mobile 
phones; thus, they tend to view technology as a way of life. They seek balance in their work and professional lives, valuing less formality/more flexibility in the work environment and career advancement opportunities [31, 52]. GenXers are less concerned with organizational loyalty, preferring to further their careers [30].

Millennials: Millennials have been entering the workforce in significant numbers [30], Increases in globalization have shaped the of this high-tech-savvy generation's core values, who also seek work-life balance $[11,29,52,30]$. They have a can-do attitude, are very technologically literate, pursue achievement and promotions in work, and represent a growing influence on work practices and employment relationships [29, 31].

\subsection{Generational Theory}

Initial conceptualizations of the notion of a generation emerged from ancient Greece and Egypt, which linked one's generation to family, lineage, and age. In ancient Greece, humans were connected to creatures and spirits according to distinctive phrases of life and the afterlife, all of which were tied to religious rituals $[32,15]$. A person's connection to the stars was a method for tracing one's existence using lineage and kinship, encompassing the life cycle of childhood, adulthood, and old age [32]. While the rituals performed by the ancient Greeks and Egyptians were highly associated with "kinds of people who lived in the kinds of times" [32]", the Egyptians' viewpoint aligned with the work of generational theory.

The most notable literature on generational theory is associated with the seminal work of Karl Mannheim (1893-1947). He purported that the notion of a generation personifies a collective identity or awareness formed by a range of influential events that impacted social processes and activities [62]. Extant literature posits that group members of the same age would have the same needs, ways of thinking, and similar values, which increases social identity, while those with different values create intergenerational conflict and differences in the organizational context [40].

Generational theory focuses on aging and the progression of one's life cycle [15], which has implications for the nature of time, biology, social connections, discourse, and transmission of knowledge $[15,33]$. Generational members often share a common economic status (class position), birth year or age (common location), and experiences that lead to similar patterns of thought and shared characteristics (social-historical process) [63]. One creates a relationship with and identifies with a generation during the formative years of youth, which then permeates a worldview that will likely differ from others born at other times [12,33]. Once the initial perception of experiences form, individuals refer to those experiences to evaluate more recent experiences [39].

Members of a generation were considered a distinct group wherein individual members share physical proximity (or spatial proximity)[63]. Accordingly, people who exist in a common location and share a historical dimension would likely share similar experiences, cultural stimuli, and developmental influences [62, 16]. In short, generational theory assumes that individuals not only share a common space in history, proximal birth years, and shared experiences, but that their similar experiences shape and create a generational uniqueness and affinity that bond its members [34, 62, 35]. The Post-World War I era, which ushered in changes in manufacturing, technology, and cross-cultural interactions, began to expand earlier conceptualizations of generations and served to diminish ties to genealogical kinship $[32,33,36]$. As such, two perspectives of generations became prominent in social sciences: the perspective of social forces and the cohort perspective [25].

Social influences and past (or present) experiences can result in generational shifts in attitudes and heritage, physically and intellectually [62]. These changes perpetuate shifts in culture, workplace dynamics, and shared social perspectives [62]. Individuals' shared experiences become a stratified sense of right and wrong that affects how one lives and communicates within society, which is continually changing as people are born and die [62]. From a cohort perspective, shared experiences are responded to differently based on one's stage in life [36], as well as one's economic and political experiences during their formative years.

Five characteristics are associated with generational theory:

[a] new participants in the cultural process are emerging, [b] former participants are continuously disappearing, [c] members of any one generation participate in a temporally limited section of the historical process, [d] generations continually transmit the accumulated cultural heritage, and [e] transition from generation to generation is a continuous process. [62]",

A refined conceptualization of generational theory refers to cohorts or individuals who share a typical habitus, hexis, and culture $[25,26]$. Hexis is a mode of thought and action that shapes attitudes and behavior [25]. A generational habitus is a cohort of people born at a specific time [38]. "Dispositions that generate and structure individual practices and which emerge and are defined by the forces operating in a particular generational field" [37]". Cultural habitus generated substantial social change between generations and on corporate governance [41]. Scholars argue that individualized experiences create variations in values and attitudes toward work within a generation [34, 38, 40, 63].

Many scholars have referenced Mannheim's common location in historical time as a shared consciousness, shaped by historical events of life course, and experiences [37, 42, 63]. To be considered members of the same generation, people must share similar experiences and cultural information, create an affinity, and share an identity [39, 62]. However, the exchange of knowledge between members of one generation and the next are either accepted or rejected, influencing values and social norms [23].

The emphasis of generations as social change agents stems from the collective identities to socio-political opinions that represent an intellectual movement [34, 62]. For example, during the first half of the twentieth century Judaic intellectuals were influenced by the Depression, Hitler and Fascism, and The Holocaust, which created a generational membership of unique cultural dimensions [34]. Traumatic 
events such as war and political upheavals are part of the socio-historical process of shared experiences and perspectives that can profoundly impact generational identity, although traumatic events may be important to some, and unimportant to others $[34,63]$.

A fundamental tenet of generational theory is concerned with the interaction between generational members and how they shape employee behavior and socialization in an organizational context. Younger generations are liable to challenge existing norms, traditions, and social patterns in the workplace, creating a power struggle between established individuals in the workforce and newcomers in the workforce thereby, becoming a driving force of change [40-42, 63]. The dynamics of generational interactions change over time with the potential to become an impetus for social change and economic prosperity $[15,30]$ Researchers have suggested that generational members tend to agree in areas of work values and personality. Because individuals are living longer and have access to technology, they are sharing more common experiences furthering the ambiguity of age-based delineations [15, 25, 37] Each generation has the potential to transform pre-existing norms about established behaviors by accepting or defying those norms, which serves to differentiate one cohort from another $[15,36,40,52,62,40,62,64]$. Kinship or genealogical linkages between generations are typically shared with successors in future generations [40]. However, those on the cusp could experience the crossover effect, in that their birth year bridges two generations, making them likely to identify with historical events in either generation [10]. The exchange of knowledge between generations supports the notion of theoretical differences among the cusp cohorts, and aid organizational leaders to distinguish how life's matters impact worldviews in order to utilize elements that promote achievement and advancement [64]. The motivational factors described prompted this study of definitions of meaningful work for GenXers and Millennial Cuspers.

Scholars have relied on age-based generational theory to identify intergenerational differences concerning definitions of meaningful work [3]. The differences among and between generations can have significant implications in the workplace regarding working conditions, employee productivity, retention, and organizational performance [27]. Indeed, organizational leaders are using generational differences as an opportunity to align business goals with the cultural norms of each generation so that individuals can work together harmoniously side-by-side [23].

\subsection{Generations and Meaningful Work}

The concept of meaningful work is grounded in a Kantian philosophy, which presupposes that meaningful work is freely entered, allows employees autonomy, provides a living (or better) wage, supports moral advancement, and does not interfere with an employee's conception of workplace happiness [7]. Meaningful work evolved from humanistic psychologists who investigated humans' actions to fulfill their inherent needs, positing that people become self-actualized once their needs are fully met $[66,45]$. Once basic survival needs are met, one's needs move to higher-order needs that translate into values, meaningfulness, life, and purpose. In effect, one continuously strives to be fully realized $[5,45]$.

From a philosophical perspective, meaningful work defines a person's sense of self, including values, beliefs, and the extent to which one's work reflects professional desires [5]. Increasingly, meaningful work has come to be associated with the concept of how people integrate work and life into every aspect of one's life to include labor, family, and friends [5]. Indeed, meaningful work is expressed as a powerful sense of achieving wholeness and coherence in life, something akin to a basic human need [13]. Similarly, writers defined meaningful work as significant and positive in valence (meaningfulness) [46-47].

Meaningful work is a subjective concept that is defined in the scholarly literature [1, 13]. The breadth of meaningful work in organizational studies is linked to different conceptualizations. For example, some link meaningful work to the amount of control they must achieve in the workplace [5], or the degree to which work tasks fulfill both intrinsic and extrinsic values and authentic living $[13,18]$. People can be responsible for their decisions in life [13, 48]. Meaningful work is an existential term cited by psychology researchers that meaningfulness is not prescribed but rather, external things or ideas that individuals find significant create a model for meaning that directs attitudes and intelligence [48, 50]. Indeed, meaningfulness at work is linked to purpose and calling as personal fulfillment, allegiance, loyalty, and attachment to one's organization $[1,65,46]$.

Despite nuanced definitions of the term, scholars generally agree that meaningful work is fostered by an organizational culture that increases employee motivation and attachment through supportive leadership and employee engagement strategies that contribute to workplace happiness and employee well-being [48, 49]. While meaningful work can be different for everyone, organizations will be better served by providing employees opportunities for creating meaning in their work [50].

All individuals, regardless of their generational cohort, aspire to meaningfulness at work through personal and professional growth and development opportunities. However, there may be significant generation-based differences in prioritizing goals and engaging in meaningful work practices. Indeed, there is a growing body of research using qualitative and quantitative approaches examining generational differences in work-based preferences and career experiences at all levels of the organization.

Researchers of organizational sciences have identified statistically significant results regarding generational differences in various organizational contexts [24, 26, 3]. For example, GenXers have expressed the belief that a meaningful job would enable them to pursue career goals. In contrast, Millennials have indicated that a meaningful job must emphasize personal happiness and fulfillment [3]. There is a consensus among researchers who agree that meaningful work derives from fostering cultures that implement employee motivation strategies through leadership ability, engagement 
strategies, and employee well-being [18, 50] These characteristics of meaningfulness are in alignment with GenXers and Millennials who desire steady progression in career, goal attainment, employee involvement, and work-life balance $[47,3]$.

The study of generations and work-related values are a central concept researched in the scholarly literature [16], including the potential to assist employers in implementing generation-specific motivational factors that foster achievement and advancement [64]. Scholars agree that work-related values and desires for advancement are similar across generations $[11,3]$. In contrast, individual perspectives on achieving personal fulfillment and meaningful work may differ between generational cohorts. Factors such as social engagement, economic status, work-life balance, and the level of effort one is willing to put forth to achieve goals may differ [17-18]. Since the birth years of individuals born on the cusp span more than one generation, their perceptions and values may also align with more than one generation.

The more excellent representation of women across all realms of work has expanded conversations on how employees define meaningful work and significantly jolting workforce dynamics [51]. Moreover, the subject of diversity between generational cohorts is driving changes in workplace values $[11,52,30]$. For instance, women continue to be concerned with work-life balance, which has been referenced in extant literature as a value for organizations who want to cultivate synergy among Gen $\mathrm{X}$ and Millennial Cuspers in their work settings [28, 52-54]. Thus, in addition to considering differences between generations, employers must also consider how definitions of meaningful work could be gender-based.

\subsection{Theoretical Orientation for the Study}

The study's theoretical orientation is that GenXers and Millennials Cuspers, representing a sub-group of their bookend generations, influence interactions and behaviors in the workplace and draw upon social identity, self-categorization, individual values, and preferences within generational cohorts [54]. Generational theory served as a foundation for this study because of its importance in defining generations as a social phenomenon $[62,36]$. Figure 1 provides a graphic representation of the theoretical orientation, with meaningful work serving as the dependent variable (DV), the cusp generation and gender serving as the independent variables.

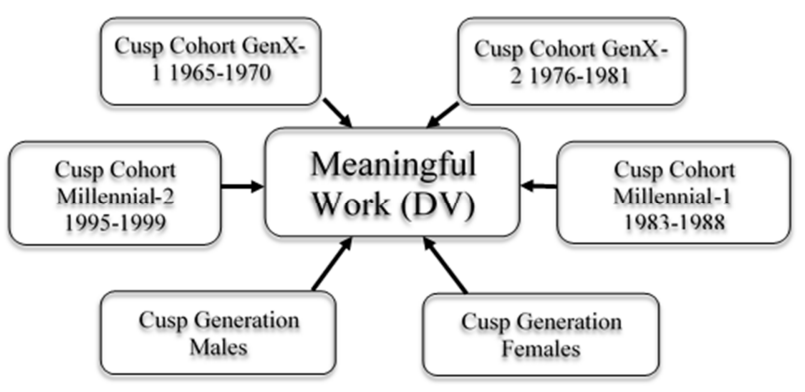

Figure 1. Conceptual framework for the study. Population and Sample.

\section{Research Design}

This quantitative, non-experimental study used statistical analyses to measure the relationships between the variables of interest, based on numerical data that emerged from the study's three research questions:

RQ1: What are the generational differences in definitions of meaningful work among the cusp cohorts of GenXers and Millennials and between gender?

RQ2: To what extent are there significant generational differences in definitions of meaningful work among the cusp cohorts of GenXers and Millennials?

RQ3: To what extent are there significant generational differences in meaningful work between gender in the cusp cohort of GenXers and Millennials?

As was employed in the current study, nonexperimental designs use surveys or polls to obtain a sample from the population and make inferences about the population based on the sample data $[55,58]$. Rating scales have using Likert-type measurements are easy to use, and understand by respondents, and are most widely used to measure people's attitudes [55-56]. Since this quantitative study was designed to determine the attitudes, traits, and characteristics of a specific cohort of human subjects - namely, individuals born within the cusp cohorts of GenXers and Millennial Cuspers (independent variable), and between males and females (independent variable) - a survey instrument in the form of the 28-item Comprehensive Meaningful Work Scale (CMWS) [13] was administered. Participants were required to answer three screening questions and four demographic questions.

\subsection{Population}

The target population for this study was GenXers and Millennial individuals born during the first four years or the last four years of their generations. As shown in Table 1, the Bureau of Labor Statistics, US. Department of Labor estimated the total number of employed individuals in the US workforce between the ages of 20 and 54 was over 112 million for the Year 2019 [79]. Approximately 48 million people were between the ages of 20 to 37, and 64 million people were between the ages of 38 to 54 [79]. Note that the number of individuals in each of the three workforce generations; the associated cusp cohort generation as a population percentage was not determined.

Table 1. Employed Individuals in the U.S. Between the Ages of 20 and 54.

\begin{tabular}{lll}
\hline Population Name & Population & \% of Population \\
\hline Total Estimated U.S. Workforce & $153,000,000$ & 100 \\
Gen X (1965-1981) & $48,000,000$ & 31.4 \\
Millennials (1982-1999) & $64,000,000$ & 41.8 \\
Total & $112,000,000$ & 73.2 \\
\hline
\end{tabular}

Note. Rounding errors, percentages may not equal $100 \%$.

\subsubsection{Procedures}

Participant Selection: Stratified random sampling, which involves dividing a population into smaller groups (strata) who share attributes or characteristics, was used to identify 
participants for this quantitative investigation. The birth year was selected as the primary strata for the study. Participants were required to be at least 18 years of age, employed with their job in a full-time capacity for at least one year at the time of survey, and employed in the U.S. in a white- or blue-collar occupation as a non-professional, semiprofessional, or professional. Respondents who did not meet any of these criteria were disqualified.

SurveyMonkey was selected as the panel vendor. SurveyMonkey hosts data on thousands of individuals, including 23,000 individuals specific to the four generational cusp cohorts requested for the study. SurveyMonkey conducted a random sampling of participants to help acquire legitimate data worthy of analysis that could possibly be generalized to the larger population [58]. SurveyMonkey managed the administration, recruitment, and collection of samples and provided a separate privacy policy for registered participants. The number of specific individuals on each cusp cohort was unknown to SurveyMonkey at the time of data collection. The study used a random sample selected from participants based on SurveyMonkey's database of volunteer participants who fit the inclusion criteria.

SurveyMonkey was provided with birth year demarcations for each cusp cohort group and instructions to assign participants to those specific groups based on the birth year category. The categories included four separate groups based on the participants' birth year. Participants who identified their birth years falling between 1965-1969 were assigned to Cohort Year 1 (GenXers-1). Participants who identified their birth year falling between 1977-1981 were assigned to Cohort Year 2 (GenXers-2). Participants who identified their birth year falling between 1982-1986 were assigned to Cohort Year 3 (Millenial-1). Participants who identified their birth year falling between 1995-1999 were assigned to Cohort Year 4 (Millennial-2).

SurveyMonkey sent 500 invitations via email to randomly selected panel members who met the inclusion criteria. The birth year was selected as the strata by entering age demarcations for each audience panel desired, using the Collect Responses tab of SurveyMonkey's dashboard. SurveyMonkey was instructed to close each panel when reaching the maximum number of 50 responses per cohort. Participants were presented with the following screening questions:

1. Which of the following includes the year you were born: 1965-1969, or 1977-1981, or 1982-1986, or 1995-1999, or none of above? (Please select one.)

2. Do you live and work in the United States? (Please respond yes or no.)

3. Have you been employed with your current employer for at least one year? (Please respond yes or no.)

4. Do any of the following describe your professional background: Blue-collar/unskilled, Administrative, Managerial, or Professional? (Please respond yes or no.)

5. Is your formal education level High School Diploma, Associates Degree, Bachelor's Degree or Graduate level (Masters, or Doctorate)? (Please respond yes or no.)
A selection of none for Question 1 disqualified the respondent and routed them to a thank-you page that ended the survey. Questions 2, 3, 4, and 5 also required a yes response, which then advanced the respondent to the next question. A no response disqualified the respondent and routed them to the thank you page that ended the survey. Scholars note that $20 \%$ of collected responses fail during the screening process [57]. Once agreeing to the informed consent form for inclusion, respondents advanced to the central survey instrument.

\subsubsection{Data Collection}

SurveyMonkey assigned an ID to each participant and tracked the time each participant started and ended the questionnaire. SurveyMonkey collected data via the password-protected website. The survey took approximately eight minutes for participants to complete, with five minutes being the shortest completion time and ten minutes being the longest. Once the required number of responses was obtained, SurveyMonkey sent an email indicating the data collection was complete. After SurveyMonkey completed the data collection, the data were downloaded using SurveyMonkey's export function directly to a password-protected personal computer and into an Excel spreadsheet.

Any records that were missing or incomplete were rendered unusable and removed from the dataset. Each participant was assigned a cusp cohort category, labeled as male or female, and assigned an aggregate meaningful work score. Scores that were deemed usable were uploaded to SPSS 25.

After removing incomplete records from the dataset, the data were sorted in ascending order by respondent ID number using Microsoft Excel. Each participant identified a specific cusp cohort year: Cohort Year 1 (GenXers-1), Cohort Year 2 (GenXers-2), Cohort Year 3 (Millenial-1), Cohort Year 4 (Millenial-2). Each participant identified their gender as either male (1) or female (2). The raw data were uploaded to SPSS 25 for analysis. Apart from aggregating the scores for meaningful work, the scores for cusp cohort years and gender, the survey items in did not require recoding, reversing, or relabeling.

\subsection{The Instrument}

The Comprehensive Meaningful Work Scale (CMWS) [13] was used to measure meaningful work according to respondents. The CMWS is a 28 item, 5-point Likert scale measure designed to determine the value employees attached to four dimensions that constitute sources of meaningful work from their perception. They indicated the extent these sources were significant to wellbeing at work. The four dimensions of the CMWS measure (a) unity with others, (b) expressing full potential, (c) developing and becoming self, and (d) serving others. Participants were asked to measure the importance of each dimension when at work. Responses ranged from 1, not at all important, to 5, very important. Participants measured the level of importance to questions such as "I have a sense of belonging," or "I can talk openly about my values when we are making decisions," or "We 
enjoy working together." It was anticipated the CMWS would reveal useful information regarding elements of meaningful work [59]

Researchers have evaluated the CMWS for its viability in defining and operationalizing meaningful work as a multidimensional construct. [59, 61]. The CMWS was empirically distinct from concepts such as calling, work engagement, intrinsic motivation, and other work values, resulting in convergent and divergent validity ranging from 0.17 to 0.69 with a comparative fit index (CFI) of .090 [59, 62]. The internal reliability measured Cronbach's $\alpha=0.72$ to 0.92 , establishing an acceptable reliability level $[59,60$, 61]. In support of CMWS' viability, other studies using a sample of university students measured Cronbach's $\alpha=0.91$ and 0.92 [2].

\section{Results}

Description of Sample: The sample frame for the study was provided by SurveyMonkey's audience panel and comprised GenXers and Millennials who were born in the cusp years of their generation and were employed with their current employer for at least one year. Of the possible $\sim 23,000$ potential participants who met the study's targeted criteria, SurveyMonkey generated 427 potential respondents through their online portal. Two hundred sixteen potential participants did not meet the inclusion criteria; 211 respondents met the inclusion criteria and completed the survey. Table 2 reflects the sample breakdown and the percentage of total responses available for analysis.

Table 2. Survey Response Rate.

\begin{tabular}{lll}
\hline Outcome & $\boldsymbol{N}$ & $\boldsymbol{\%}$ \\
\hline Invitations Sent & 500 & 100.0 \\
Responded to invitation & 427 & 85.0 \\
Exited at informed consent & 16 & 3.7 \\
Did not finish/Incomplete Responses & 200 & 45.1 \\
Completed surveys & 211 & 49.4 \\
\hline
\end{tabular}

Note. Rounding errors, percentages may not equal $100 \%$.

The participant sample representing GenXers and Millennials born within cusp cohort years was segmented by gender. The final sample of 211 responses included 87 males (41.2\%), 123 females (58.3\%), and one participant who chose not to declare gender and whose data were removed from the analysis. Birth year assignments for the cusp cohort groups, adopted from extant literature [60], were labeled GenXers-1 (1965 to1969), GenXers-2 (1977 to 1981), Millennial-1 (1982 to 1986), and Millennial-2 (1995 to 1999) [10]. The cusp cohort groups, which were initially labeled by the actual cohort year, were renamed under from Cohort Year, 1, 2, 3, and 4, to (GenXers-1) (GenXers-2) (Millennial-1), and (Millennial-2), respectively. The participant numbers in each sample group for the four cohort years were $51(24.1 \%), 55$ (26\%), 59 (28\%), and 46 (22\%) for Cohort Year 1, 2, 3, and 4, respectively. Table 3 reflects the participants in each cusp cohort year and gender for the one-way ANOVA analysis.
Table 3. Demographics for Gender and Cohort.

\begin{tabular}{lll}
\hline Variable & $\boldsymbol{n}$ & $\boldsymbol{\%}$ \\
\hline Gender & & \\
Male & 87 & 41.2 \\
Female & 123 & 58.3 \\
Not declared & 1 & 0.5 \\
Cohort & & \\
Gen X-1 (1965-1969) & 51 & 24.2 \\
Gen X-2 (1977-1981) & 55 & 26.1 \\
Millenial-1 (1982-1986) & 59 & 28.0 \\
Millenial-2 (1995-1999) & 46 & 21.8 \\
\hline
\end{tabular}

This study used a one-way ANOVA analysis, requiring that six assumptions be met before conducting the analysis: (1) the dependent variable should be measured at the interval or ratio level; (2) the independent variable must include two or more categorical independent groups; (3) there should be independent observations; (4) there should be no significant outliers; (5) there should be normality between the independent and dependent groups; and (6) there should be homogeneity of variances across the independent and dependent variables. SPSS 25 was used to test each assumption.

The first assumption of ANOVA requires a dependent variable measured at a continuous level [67]. Scores from the dataset that measured meaningful work were aggregated and used as one score for each participant's response. Since the dependent variable was interval data, which met this assumption.

The second assumption of ANOVA requires the independent variables to consist of at least two or more categorical groups [67]. The independent variable, cusp cohort group, was categorized into four levels determined by birth year which met this assumption.

The third assumption of ANOVA requires independence of observations [67]. More specifically, the relationship between each group of independent variables must have no relationship and be observed independently. Random participant selection of each group was conducted, and the option to split the data file was selected in SPSS 25. As such, output using calculations for each independent group helped to meet this assumption. Different participants were in each group, which helped to meet this assumption.

The fourth assumption of ANOVA requires that the data be devoid of significant outliers, which are data points that deviate markedly from others [67]. To determine the presence of outliers, analysis using the explore option of SPSS 25 was implemented. The researcher conducted a visual examination of normal Q-Q plots and boxplot graphs. Within the dataset, nine outliers were identified on the box plots, which typically lie beyond a plot's whiskers.

The most common methods used to address outliers include correcting data points to an actual value, replacing the outlier value with less extreme values, or eliminating the data point [68]. The protection of participant anonymity prohibits the option to contact participants to clarify responses after data collection[68], which influenced the rationale and method 
used to address the outliers. A winsorizing method was used, which refers to replacing or modifying the smallest and most significant data points with the observations closest to other sample values to limit any outlier effects.

The winsorizing method allows the replacement of data points, and the sample size, and statistical power will remain the same [69]. For example, if an extreme value rests below the plot's whiskers (or more than 1.5 box lengths from the plot's whiskers), modifying the data point to a number that is at the line of the plot's whiskers would render the data point less extreme, creating the opportunity to remove the outlier. The process of winsorizing was performed for each extreme data point identified as an outlier. Once the data points were modified, the procedure to detect outliers using the explore option was conducted again., As assessed by visual inspection of box plot graphs, no further outliers were identified, which met this assumption.

The fifth assumption tested for ANOVA requires a normal distribution within the dataset [67], which was conducted using the Shapiro-Wilk test for normality for the dependent variable, meaningful work, based on cohort year and gender. The assumption for normality is met when $p=>.05$ and considered not significant. In contrast, the assumption is violated with a significance level, $\mathrm{p}<.05$. As assessed by Shapiro-Wilk Test, the data were not normally distributed by cusp cohort years, in that the four cohorts had a $p=<.05$. The assumption for normality was not met. Similarly, the assumption for normality relating to gender was not met for males or females, $\mathrm{p}=<.001$. The assumption for normality was violated for the independent variables. The results are presented in Table 4.

Assumptions of ANOVA analysis vary. Researchers posit that ANOVA can be considered robust to nonnormality and have little effect on Type I error performance and statistical power, inferences in the means when group sizes are small and of similar size [43,80 - 84]. Moreover, "the relevant question is not whether ANOVA assumptions are met, but rather whether the plausible violations of assumptions have consequences on validity of probability statements based on standard assumptions" [81]." Furthermore, very few datasets have a normal distribution [84].

Table 4 Test for Normality by Cohort Year and Gender.

\begin{tabular}{llc}
\hline Variable & Meaningful Work & \\
\hline & Shapiro-Wilk Test Statistic & $\boldsymbol{p}$ \\
\hline Cohort & & \\
Gen X-1 (1965-1969) & .947 & .023 \\
Gen X-1 (1977-1981) & .937 & .007 \\
Millenial-1 (1982-1986) & .936 & .004 \\
Millenial-2 (1995-1999) & .872 & $<.001$ \\
Gender & & \\
Male & .925 & $<.001$ \\
Female & .937 & $<.001$ \\
\hline
\end{tabular}

Note. The cusp cohorts were delineated using the listed birth year.

ANOVA's sixth assumption assumes that the population variances of independent variables be equal for the groups of independent variables [70]. Homogeneity of variances was tested using Levene's test of equality of SPSS 25 for the cohort year and again for gender on the dependent variable. The assumption is considered met if results are not significant, $p>.05$. The assumption of homogeneity of variances relating to the cusp cohort year was not violated and considered not significant, $\mathrm{p}=>.05, \mathrm{~F}(3,207)=1.21, \mathrm{p}=.306$. For gender, homogeneity of variance was met, as Levene Test assessed for equality of variances, $\mathrm{F}(1,208)=0.89, p=.345$. The results are listed in Table 5.

Table 5. Homogeneity of Variance by Cohort Year and Gender.

\begin{tabular}{lll}
\hline Variable & Meaningful Work & \\
\hline & Levene's Test Statistic & $\boldsymbol{p}$ \\
\hline Cohort & 1.212 & .306 \\
Gender & 0.890 & .345 \\
\hline
\end{tabular}

Note. The Cohort includes Gen-X and Millennials; Gender includes males and females.

Measures of central tendency, as reflected in the a priori analysis, were examined. Minimum, maximum, standard deviation, and standard error were examined for each variable. Table 6 provides the descriptive statistics for meaningful work based on cusp cohort years. Table 7 provides the descriptive statistics for meaningful work based on gender.

Table 6. Descriptive Statistics for Meaningful Work by Cohort.

\begin{tabular}{llllll}
\hline Variable & $\boldsymbol{n}$ & Min & Max & $\boldsymbol{M}$ & $\boldsymbol{S D}$ \\
\hline GenX-1 (1965-1969) & 51 & 70.00 & 140.00 & 112.04 & 19.091 \\
GenX-2 (1977-1981) & 55 & 80.00 & 140.00 & 116.25 & 17.057 \\
Millennial-1 (1982-1986) & 59 & 70.00 & 140.00 & 110.86 & 18.718 \\
Millennial-2 (1995-1999) & 46 & 70.00 & 140.00 & 115.52 & 22.373 \\
\hline
\end{tabular}

Note. $\mathrm{M}=$ mean; $\mathrm{SD}=$ standard deviation

Table 7. Descriptive Statistics for Meaningful Work by Gender.

\begin{tabular}{llllll}
\hline Variable & $\boldsymbol{n}$ & $\boldsymbol{M i n}$ & $\boldsymbol{M a x}$ & $\boldsymbol{M}$ & $\boldsymbol{S D}$ \\
\hline Male & 87 & 70.00 & 140.00 & 113.21 & 18.333 \\
Female & 123 & 70.00 & 140.00 & 114.15 & 19.690 \\
\hline
\end{tabular}

Note. $\mathrm{M}=$ mean; $\mathrm{SD}=$ standard deviation

A one-way ANOVA was used to compare possible combinations of groups for each independent variable. The following represents the steps taken to test Hypothesis 2 using a one-way ANOVA model: Ho: $\mu 1=\mu 2$, Ha: $\mu 1 \neq \mu 2$. Recall that Hypothesis 2 pertains to differences in definitions of meaningful work within GenXers and Millennials cusp cohorts. A one-way ANOVA was conducted to determine whether their differences in group means within GenXers and Millennials cusp cohorts. The model was repeated to test Hypothesis 3. The participants were categorized into four groups: Cohort Year 1 (GenXers-1) where $\mathrm{n}=51$; Cohort Year 2 (GenXers-2), where $\mathrm{n}=55$; Cohort Year 3 (Millennial-1), where $\mathrm{n}=59$; and Cohort Year 4 (Millennial-2), where $\mathrm{n}=46$. The differences between these groups were not statistically significant, $F(3,207)=1.009, p=.390$, partial $\eta 2=.014$. Because there was no significance found in the F test, post hoc analyses were not conducted. The null hypothesis was not rejected, suggesting the lack of significant differences in meaningful work scores by the cusp cohort. Table 8 presents 
the results of ANOVA by the cusp cohort.

Table 8. ANOVA for Meaningful Work by Cusp Cohort.

\begin{tabular}{lllll}
\hline Source & $\boldsymbol{d} \boldsymbol{f}$ & $\boldsymbol{F}$ & $\boldsymbol{p}$ & partial $\boldsymbol{\eta}^{2}$ \\
\hline Cohort & 3 & 1.009 & .390 & .014 \\
Error & 207 & & & \\
Total & 211 & & & \\
\hline
\end{tabular}

Note. The Cohort includes Gen-X and Millennials.

Hypothesis 3 addresses differences in means between males and females. A one-way ANOVA was conducted to determine the mean differences of meaningful work for males and females. Participants were categorized into two groups: males $(\mathrm{n}=87)$, and females $(\mathrm{n}=123)$. The differences between gender were not statistically significant, $F(1,208)=0.125$, p $=.724$, partial $\eta 2=.001$. The null hypothesis was not rejected, suggesting no significant differences in meaningful work scores by gender. Table 9 presents the results of ANOVA by gender.

Note. $\mathrm{M}=$ mean; $\mathrm{SD}=$ standard deviation the content is correct

Table 9. ANOVA for Meaningful Work by Gender.

\begin{tabular}{lllll}
\hline Source & $\boldsymbol{d} \boldsymbol{f}$ & $\boldsymbol{F}$ & $\boldsymbol{p}$ & partial $\boldsymbol{\eta}^{2}$ \\
\hline Gender & 1 & 0.125 & .724 & .001 \\
Error & 208 & & & \\
Total & 210 & & & \\
\hline
\end{tabular}

Note. Gender includes males and females.

\section{Summary}

The study was designed to examine whether there were differences in definitions of meaningful work between GenXers and Millennial Cuspers, as well as between male and female participants. The research design extends generational research scholars' work regarding whether individuals on the cusp of their generations have differing perceptions of meaningful work. The CMWS was used to collect data from a total respondent cohort of 211 individuals who met the inclusion criteria regarding the specific factors they identified as adding meaning to their work lives.

A quantitative cross-sectional research methodology was applied to measure the independent variables, cusp cohort years (separated into four levels), and gender. Two one-way ANOVAs were conducted: the first to measure differences between cusp cohort groups, and the second to measure differences between gender. The results were not significant GenXers and Millennials cusp cohorts, $p=.390$; nor were the results significant for gender, $\mathrm{p}=.979$. Nonetheless, more similarities regarding meaningful work among the cusp cohorts and gender were found than anticipated.

Initially, the study was designed to incorporate a two-way ANOVA to determine the interactions between gender within the cusp cohort year. However, the data were insufficient to conduct a two-way ANOVA; thus, the hypotheses for RQ1 were not tested.

A one-way ANOVA was conducted to test the second set of hypotheses, which assessed for differences in meaningful work by cusp cohort. The results were not statistically significant at a level of $p=.390$. Tukey post hoc testing was not conducted as no statistical significance was found between the group means in the cusp cohorts of GenXers or Millennials. As such, the null hypothesis for RQ2 was not rejected.

A second one-way ANOVA was conducted to test the third set of hypotheses, which assessed for differences in meaningful work by gender. The analysis from Hypothesis 3 resulted in a nonsignificant result; $p=.724$, suggesting no statistically significant differences in meaningful work scores between males and females. As such, the null hypothesis for RQ3 was not rejected.

Research studies measuring generational differences in various contexts have contributed to organizational and management sciences $[24,13,3]$. The current study adds to the body of knowledge regarding how generational research can contribute to changes in the workplace that accommodate employees' evolving needs. The study shows that individuals in cusp cohorts perceive meaningful work as valuable, define meaningful work similarly to GenXers and Millennials, and that differences were not as pronounced as expected.

Although a significant range of studies support generational differences at work, researchers of behavioral sciences prefer an approach whereby individuals select generational memberships based on how they identify with a generation, rather than being assigned a generation based solely on birth year [71-72]. This study's findings indicate a higher degree of similarity within the cusp cohorts regarding their perceptions of meaningful work than anticipated, which calls into question why individuals on the cusp identify with more than one generational cohort. Although existing evidence is challenging to aggregate and generational boundaries are not impermeable, different methodologies, conceptualizations, and different collection periods may bring additional consistency to generations' inquiry[35, 43, 54]. Employing a mixed-methods or qualitative approach that facilitates multiple response methods may provide more reliable and valid measurements of generational differences.

\section{Discussion}

Each generation shares characteristics based on similar birth years and social or political events or influences, and that these shared influences guide work-related preferences [25]. Traditionalists (born 1922 to 1945) and Baby Boomers (born 1946 to 1964) continue to retire in large numbers from the workforce-with younger cohorts replacing them - challenging employers to develop work environments that foster employee commitment and retention while also seeking to accommodate their generation-specific requirements $[39,25,61]$.

The scholarly literature focuses on differences among generations and their contributions to changes in the social and intellectual structure of work environments. The dynamic relationships between and among generations continue to shape cultures, societal norms, and workplace values $[9,73]$. 
Because scholars and practitioners continue to debate whether generational differences even exist-and if so, are they significant [20-21]. This study was designed to learn more about those on the cusp of their generations and if meaningful work continues to be at the forefront of employee happiness at work [21].

Recall that three questions guided this study, the goal of which was to determine any differences in definitions of meaningful work between GenXers and Millennial Cuspers based both on birth year and gender. This study relied on earlier research to examine what constituted meaning at work, the obligations that exist on the part of organizations to foster meaningful work opportunities within their work environments, and ethical responsibilities on the part of individuals to pursue meaningful work [3, 6, 17-18, 49-50]. A summary of the results, according to each research question follows.

RQ1: What are the generational differences in definitions of meaningful work among the cusp cohort of Gen $\mathrm{X}$ and Millennials and between gender?

Because of the small respondent cohort, insufficient data was collected to examine and analyze this research question.

RQ2: To what extent are there significant generational differences in meaningful work among the cusp cohort of Gen $\mathrm{X}$ and Millennials?

The results showed no significant differences between definitions of meaningful work between of Gen $\mathrm{X}$ and Millennials cusp cohort.

RQ3: To what extent are there significant generational differences in meaningful work between gender in the cusp cohort of Gen X and millennials?

The results showed no significant differences in meaningful work between gender.

A recent qualitative study using the CMWS [3] was conducted to determine how generational cohorts prioritize sources of meaningful work. In this investigation, definitions of meaningful work fell within CMWS' four-quadrant model: developing and becoming, unity with others, expressing full potential, and serving others. The evidence supported the employers' rationale to ascertain what is important to employees, how best to enable them to fulfill their self-developed purpose, and foster meaning using work-life balance-while still meeting organizational goals. The researchers posited that all generations value meaningful work and tend to define meaning using intrinsic and extrinsic rewards. The authors concluded that while generational differences remain rich and complex, and that assessing commonalities and differences across generations is worthy of study, all generations of workers share a similar goal of developing and becoming themselves in the workplace. Indeed, employees expect their employer's values to be in alignment with their own, have occasion to take part in decision making, as well as have challenging work influence meaningfulness and hinder workers' inclinations to quit [21, 44, 74]

A cross-sectional study was conducted to examine meaningful work across generations and their influence on work engagement. While results revealed significant differences between Baby Boomers, GenXers, and Baby
Boomers, and Millennials, they found no differences between GenXers and Millennials [1]. The findings detailed in this report partially support generational differences but the inconclusiveness of research on generational differences and the potential of its similarities [1]. Note that the current study captured data from individuals on the cusp of GenXers and Millennials rather than across generations, which resulted in no significant difference ( $\mathrm{p}=.390)$; similarly, perceptions of meaningful work between males and females were also not significant $(\mathrm{p}=.979)$.

In another study of generational differences, researchers found that individuals, regardless of generation, desire team collaboration, involvement in decision-making regarding the work they perform, and challenging jobs [51]. Similarly, the findings from this study support the fact that differences between generations with respect to work values were negligible. Nonetheless, other researchers have suggested that because some heterogeneity between and among cusp cohorts exists, researchers should seek to explain why generational differences exist and how experiences influence the organization and employees [21].The crux of the research is that organizational leaders can enhance commitment and loyalty. [21].

The literature is replete with data on generational differences, documenting how such differences are underpinned by personal experiences that shape personality, behavior attitudes, work preferences, and career choices [23, 25]. However, the lack of significance of findings in this study as to how each cusp cohort interprets meaningful work largely contradicts the results of previous literature. Continuing to examine generational differences as a work-related phenomenon is thus worthy of continued research.

Findings from a recent study prompted the authors to conclude that "people born on the cusp of a generation would not be expected to act entirely different from a person born a mere year on the other side of the generational divide" [19]." $p$. $3)$ ]. The findings from recent literature support arguments regarding generational learning preferences for those on generational cusps, in that there were no significant differences between Baby Boomers, Gen X and Millennial cusp cohorts [19]. Similarly, the findings detailed in the literature suggest more similarities than differences in how cusp cohorts define meaningful work across generations[19]. However, other research literature indicates that while perceptions of meaningful work may change, the appreciation or value individuals place on meaningful work remains consistent [75].

The CMWS model measured drivers of meaningful work, including working cohesively, contributing to the organization, making a difference that matters, and being authentic. Meaningful work has been related to constructs such as intrinsic motivation, a calling to serve a higher purpose, work engagement, and other work-related values [76-77, 46, 17]. The constructs of meaningful work correspond to the fulfillment of an existential purpose [13]. For example, overall, unity with others, referring to having a sense of mutual values, support, and belongingness, significantly associated with 
dimensions of meaningful work. Accordingly, employers should actively seek to create conditions for meaningful work as a basic human need $[13,6]$.

\section{Conclusion}

This study was designed to examine whether there were differences in definitions of meaningful work between GenXers and Millennial Cuspers and between male and female participants. Using the CMWS as the data collection instrument, subsequent quantitative analysis was conducted to determine the specific factors that the respondents in this study identified as adding meaning to their work lives. One-way ANOVA analysis revealed that results were not significant between the cusp cohorts of GenXers and Millennials; nor was any significant correlation identified based on gender. Indeed, more similarities regarding meaningful work were found for the cusp cohorts and males/females than anticipated.

Research studies measuring generational differences in various contexts have been significant in contributing to the body of organizational sciences [24, 13, 3]. The current study supports the importance of how generational research findings can potentially contribute to workplace changes that respond to the employees' evolving needs of. The study shows that individuals in cusp cohorts perceived meaningful work to be valuable and defined meaningful work similarly regardless of their birth year.

Although perceived and actual generational differences have been reported in the scholarly literature [71, 73], other researchers have recommended an approach whereby individuals select generational memberships based on how they identify with a generation rather than being assigned a generation based on age $[72,74]$.

\section{Recommendations for Future Research}

This study focused on the generational differences in definitions of meaningful work between the of GenXers and Millennials cusp cohorts and between gender within various organizational backgrounds. The lack of statistically significant results for this study was not unexpected. Indeed, overall, researchers remain conflicted by the lack of trustworthy empirical evidence that confirms workplace differences based on generational identity [20].

One recommendation for a follow-up study is to use the CMWS instrument to measure the importance and frequency of the four dimensions of meaningful work within the cusp cohort to identify differences [78]. Such data would be useful in providing a more nuanced understanding regarding definitions of meaningful work for specific generational cohorts. Another area for future study could use qualitative approaches to investigate differences and commonalities between generations. Another important addition to the scholarly research could involve a longitudinal study with multiple data collection points to examine whether generational views of meaningful work change over time. Finally, case studies focusing on generational differences and similarities in specific organizational settings are recommended.

\section{References}

[1] Hoole, C., \& Bonnema, J. (2015). Work engagement and meaningful work across generational cohorts. SA Journal of Human Resource Management, 13(1), 1-e11. doi: 10.4102/sajhrm.v13i1.681.

[2] Dik, B. J., Eldridge, B. M., Steger, M. F., \& Duffy, R. D. (2012) Development and the calling and vocation questionnaire (CVQ) and brief calling scale (BCS) [special issue]. Journal of Career Assessment, 20, 242-263. doi: 10.1177/1069072711434410.

[3] Weeks, K. P., \& Schaffert, C. (2017). Generational differences in definitions of meaningful work: A mixed methods study. Journal of Business Ethics, 156(4), 1045-1061. doi: 10.1007/s10551-017-3621-4.

[4] Rosso, B. D., Dekas, K. H., \& Wrzesniewski, A. (2010). On the meaning of work: A theoretical integration and review. Research in Organizational Behavior, 30, 91-127. doi: 10.1016/j.riob.2010.09.001.

[5] Chalofsky, N., \& Cavallaro, L. (2013). A good living versus a good life: Meaning, purpose, and HRD. Advances in Developing Human Resources, 15, 331-340. doi: 10.1177/1523422313498560.

[6] Yeoman, R. (2014). Conceptualizing meaningful work as a fundamental human need. Journal of Business Ethics, 125 (2), 235-251. doi: 10.1007/s10551-013-1894-9.

[7] Bowie, N. E. (1998). A Kantian theory of meaningful work. Journal of Business Ethics, 17, 1083-1092. doi: 10.1023/A:1006023500585.

[8] Bencsik, A., Horváth-Csikós, G., \& Juhász, T. (2016). Y and Z generations at workplaces. Journal of Competitiveness, 8, 90-106. doi: 10.7441/joc.2016.03.06.

[9] Campbell, W. K., Campbell, S. M., Siedor, L. E., \& Twenge, J. M. (2015). Generational differences are real and useful. Industrial and Organizational Psychology, 8, 324-331. doi: 10.1017/iop.2015.43.

[10] Arsenault, P. M. (2004). Validating generational differences. Leadership \& Organization Development Journal, 25, 124-141. doi: $10.1108 / 01437730410521813$.

[11] Becton, J. B., Walker, H. J., \& Jones-Farmer, A. (2014). Generational differences in workplace behavior. Journal of Applied Social Psychology, 44, 175-189. doi:10.1111/jasp.12208.

[12] Lyons, S. T., \& Schweitzer, L. (2017). A qualitative exploration of generational identity: Making sense of young and old in the context of today's workplace. Work, Aging and Retirement, 3(2), 209-224. doi: 10.1093/workar/waw024.

[13] Lips-Wiersma, M., \& Wright, S. (2012). Measuring the meaning of meaningful work: Development and validation of comprehensive meaningful work scale (CMWS). Group \& Organization Management, 37, 655-685. doi: $10.1177 / 1059601112461578$. 
[14] Schnell, T., Höge, T., \& Pollet, E. (2013). Predicting meaning in work: Theory, data implications. The Journal of Positive $\begin{array}{llll}\text { Psychology, } & 8 & (6), & 543-554 .\end{array}$ $10.1080 / 17439760.2013 .830763$.

[15] Joshi, A., Dencker, J. C., \& Franz, G. (2011). Generations in organizations. Research in Organizational Behavior, 30, 177-205. doi: 10.1016/j.riob.2011.10.002.

[16] Nakai, Y. (2015). Why we study generations. Industrial and Organizational Psychology, 8(3), 331-334. doi: 10.1017/iop.2015.44.

[17] Schaufeli, W. B., Bakker, A. B., \& Salanova, M. (2006). The measurement of work engagement with a short questionnaire: A cross-national study. Educational and Psychological Measurement, 66(4), 701-716. doi: 10.1177/0013164405282471.

[18] Michaelson, C., Pratt, M. G., Grant, A. M., \& Dunn, C. P. (2014). Meaningful work: Connecting business ethics and organization studies. Journal of Business Ethics, 121(1), 77-90. doi:10.1007/s10551-013-1675-5.

[19] Meeks, M. D., Williams, F., Knotts, L., \& James, K. D. (2013). Deep vs. surface learning: An empirical test of generational differences. International Journal of Education and Research, 1(8), 1-15. Retrieved http://ijern.com/journal/August-2013/01.pdf

[20] Constanza, D. P., \& Finkelstein, L. M. (2015). Generationally based differences in the workplace: Is there a there there? Industrial and Organizational Psychology, 8, 308-323. doi: 10.1017/iop.2015.15.

[21] Cadiz, D. M., Truxillo, D. M., \& Fraccaroli, F. (2015). What are the benefits of focusing on generation-based differences and at what cost? Industrial and Organizational Psychology, 8, 356-362. doi:10.1017/iop.2015.49.

[22] Ng, E. S. W., \& Gossett, C. W. (2013). Career choice in Canadian public service: An exploration of fit with the millennial generation. Public Personnel Management, 42(3), 337-358. doi: 10.1177/0091026013495767.

[23] Bennett, J., Pitt, M., \& Price, S. (2012). Understanding the impact of generational issues in the workplace. Facilities, 30, 278-288. doi:10.1108/02632771211220086.

[24] Foster, K. (2013). Generation and discourse in working life stories. The British Journal of Sociology, 64(2), 195-215. doi: 10.1111/1468-4446.12014.

[25] Lyons, S., \& Kuron, L. (2013). Generational differences in the workplace: A review of evidence and directions for future research. Journal of Organizational Behavior, 35(1), 139-157. doi: 10.1002/job.1913.

[26] Kelan, E. K. (2014). Organising generations - What can sociology offer to the understanding of generations at work? Sociology Compass 8(1), 20-30. doi: 10.1111/soc4.12117.

[27] Heyns, M. M., \& Kerr, M. D. (2018). Generational differences in workplace motivation. SA Journal of Human Resource Management, 16(2), e1-e10. Doi :10.4102/sajhrm.v16i0.967.

[28] Egri, C. P., \& Ralston, D. A. (2004). Generation cohorts and personal values: A comparison of China and the United States. Organization Science, 15(2), 210-220. doi: 10.1287 /orsc. 1030.0048 .
[29] Jones, J. S., Murray, S. R., \& Tapp, S. R. (2018). Generational differences in the workplace. Journal .of Business Diversity, 18, 88-97. doi: $10.33423 /$ jbd.v18i2.52

[30] Zabel, K. L., Biermeier-Hanson, B. B. J., Baltes, B. B., Early, B J., \& Shepard, A. (2017). Generational differences in work ethic: Fact or fiction? Journal of Business and Psychology, 32, 301-315. doi: 10.1007/s10869-016-9466-5.

[31] Culiberg, B., and Mihelič ${ }^{2}$ K. (2016). Three ethical frames of reference: insights into Millennials' ethical judgements and intentions in the workplace. Business Ethics, 25, 94-111. doi: 10.111/beer.12106.

[32] Burnett, J. (2010). Generations: The time machine in theory and practice. Abingdon, OX: Ashgate.

[33] Pilcher, J. (1994). Mannheim's sociology of generations: An undervalued legacy. The British Journal of Sociology, 45(3), 481-495. doi: 10.2307/591659 Mannheim's sociology of generations: An undervalued legacy. The British Journal of Sociology, 45(3), 481-495. doi: 10.2307/591659.

[34] Eyerman, R., \& Turner, B. (1998). Outline of a theory of generations. European Journal of Social Theory, 1 (1), 91-106. doi: $10.1177 / 136843198001001007$.

[35] Parry, E., \& Urwin, P. (2011), Generational difference in work values: A review of theory and evidence. International Journal of Management Reviews, 13 (1), 79-96. doi: 10.1111/j.1468-2370.2010.00285.x.

[36] Ryder, N. B. (1965). The cohort as a concept in the study of social change. American Sociological Review 30 (6), 843-861. doi: $10.2307 / 2090964$.

[37] Gilleard, C. (2004). Cohorts and generations in the study of social change. Social Theory and Health, 2, 106-119. doi: $10.1057 /$ palgrave.sth.8700023.

[38] Benson, J., \& Brown, M. (2011). Generations at work: Are there differences and do they matter? The International Journal of Human Resource Management, 22, 1843-1865. doi:10.1080/09585192.2011.573966.

[39] Beaven, M. (2014) Generational differences in the workplace: Thinking outside the boxes Contemporary Journal of Anthropology and Sociology. 4, 68-80. Retrieved from http://encompass.eku.edu/igra/201/2014/14.

[40] Ming, S., Liu, J. J., \& Leng, Y. (2019). The relationship between senior executives' age and agency costs: A study based on inter-generational perspective. Advances in Management and Applied Economics, 9 (5), 1-23. Retrieved from https://www.scienpress.com/journal_focus.asp?Main_Id=55

[41] Bourdieu, P. (1997). Outline of a theory of practice. Cambridge, NY: Cambridge University Press.

[42] Strauss, W., \& Howe, N. (1991). Generations: The history of America's future, 1584 to 2069. New York: Harper Perennial.

[43] Li, X., Li, X., \& Hudson, S. (2013). The application of generational theory to tourism consumer behavior: An American perspective. Tourism Management, 37, 147-164 doi: 10.1016/j.tourman.2013.01.015.

[44] Brink, K. E., \& Zondag, M. M. (2019). Examining job attribute preferences across three generational cohorts. Journal of Career Development, $0894845319837384 . \quad$ doi: $10.1177 / 0894845319837384$. 
[45] Maslow, A. H. (1943). A theory of human motivation. Psychological Review, 50, 370-396. Retrieved from downloads.joomlacode.org/trackeritem/5/8/7/58799/Abraham H.Maslow-ATheoryOf Human Motivation.pdf

[46] Steger, M. F., Dik, B. J., \& Duffy, R. D. (2012). Measuring meaningful work: The work and meaning inventory (WAMI). Journal of Career Assessment, 20(3), 322-337. doi: $10.1177 / 1069072711436160$.

[47] Hackman, J. R., \& Oldham, G. R. (1980). Work redesign. Reading, MA: Addison-Wesley.

[48] Kekes, J. (1986). The informed will and the meaning of life. Philosophy and Phenomenological Research, 47(1), 75-90. doi: $10.2307 / 2107725$.

[49] May, D. R., Gilson, R. L., \& Harter, L. M. (2004). The psychological conditions of meaningfulness, safety and availability and the engagement of human spirit at work. Journal of Occupational and Organizational Psychology, 77(1), 11-37. doi: 10.1348/096317904322915892.

[50] Michaelson, C. (2011). Whose responsibility is meaningful work? Journal of Management Development, 30(6), 548-557. doi: $10.1108 / 02621711111135152$.

[51] Menci, J., \& Lester, S. W. (2014). More alike than different: What generations value and how the values affect employee workplace perceptions. Journal of Leadership \& Organizational Studies, 21(3), 257-272. doi: $10.1177 / 1548051814529825$.

[52] Smola, K. W., \& Sutton, C. D. (2002). Generational differences: Revisiting generational work values for the new millennium. Journal of Organizational Behavior, 23(4), 363-382. doi: $10.1002 /$ job. 147

[53] Gursoy, D., Chi, C. G., \& Karadag, E. (2013). Generational differences in work values and attitudes among frontline and service contact employees. International Journal of Hospitality Management, 32, 40-48. doi: 10.1016/j.ijhm.2012.04.002.

[54] Lyons, S., Urick, M., Kuron, L., \& Schweitzer, L. (2015). Generational differences in the workplace: There is complexity beyond the stereotypes. Industrial and Organizational Psychology, 8(3), 346-356. doi:10.1017/iop.2015.48.

[55] Patten, M. L. \& Newhart (2017). Understanding research methods: An overview of the essentials. United States: Routledge.

[56] Subedi, B. P. (2016). Using Likert type data in social science research: Confusion, issues and challenges. International Journal of Contemporary Applied Sciences, 3(2), 36-49. Retrieved from https://www.ijcar.net/assets/pdf/Vol3-No2-February2016/02.pdf

[57] Craig, B. M., Hays, R. D., Pickard, S. A., Cella, D., Revicki, D. A., \& Reeve, B. B. (2013). Comparison of U.S. panel vendors for online surveys. Journal of Medical Internet Research, 15, e260. doi:10.2196/jmir.2903.

[58] Field, A. (2013). Discovering statistics using IBM SPSS. Thousand Oaks, CA: Sage.

[59] Both-Nwabuwe, J., Dijkstra, M. T. M., \& Beersma, B. (2017). Sweeping the floor or putting a man on the moon: How to define and measure meaningful work. Frontiers in Psychology, 8, 1658. doi:10.339/fpsyg.2017.01658.

[60] Twenge, J. M., Campbell, S. M., Hoffman, B. J., \& Lance, C. E. (2010). Generational differences in work values: Leisure and extrinsic values increasing, social and intrinsic values decreasing. Journal of Management, 36, 1117-1142. doi: $10.1177 / 0149206309352246$.

[61] Tolbize, A. (2008). Generational differences in the workplace. Research and Training Center of Community Living, 19, 1-13.

[62] Mannheim, K. (1952). The sociological problems of generations. In P. Kecskemeti (Ed.), Essays on the sociology of knowledge (pp. 163-195). New York: Oxford University Press.

[63] Edmunds, J., \& Turner, B. S. (2005). Global generations: Social change in the twentieth century. The British Journal of $\begin{array}{llll}\text { Sociology, } & 5 & (4), & 559-577 .\end{array}$ 10.1111/j.1468-4446.2005.00083.x.

[64] Darby, V., \& Morrell, D. L. (2019). Generations at work: A review of generational traits and motivational practices impacting millennial employees. Drake Management Review, 8 (1), 1-13. Retrieved from http://faculty.cbpa.drake.edu/dmr/0812/DMR081201R.pdf

[65] Cardador, M. T., Dane, E., \& Pratt, M. G. (2011). Linking calling orientations to organizational attachment via organizational instrumentality. Journal of Vocational Behavior, 79, 367-378. doi: 10.1016/j.jvb.2011.03.009.

[66] Hertzberg, F., Mausner, B., \& Snyderman, B. B. (2007). The motivation to work. Piscataway, NJ: Transaction.

[67] Laerd Statistics (2017). Statistical tutorials and software guides. Retrieved from https://statistics.laerd.com/

[68] Aguinis, H., Gottfredson, R. K., \& Joo, H. (2013). Best-practice recommendations for defining identifying, and handling outliers. Organizational Research Methods, 16, 270-301. doi: 10.1177/1094d8112470848.

[69] Lusk, E. J., Halperin, M., \& Heilig, F. (2011). A note on power differentials in data preparation between trimming and winsorizing. Business Management Dynamics, 1 (2), 23-31. Retrieved from http://bmdynamics.com/issue_pdf/23_31.pdf

[70] Kim, K. (2016). Understanding one-way ANOVA using conceptual figures. Korean Journal of Anesthesiology, 70 (1), 22. doi:10.4097/kjae.2017.70.1.22.

[71] Lester, S. W., Standifer, R. L., Schultz, N. J., \& Windsor, J. M. (2012) Actual versus perceived generational differences at work: An empirical examination. Journal of Leadership \& Organizational Studies, 19, 341-354. doi: $10.1177 / 1548051812442747$.

[72] Wang, Y., \& Peng, Y. (2015). An alternative approach to understanding generational differences. Industrial and Organizational Psychology, 8 (3), 390-395. doi: 10.1017/iop.2015.56

[73] Chaney, D., Touzani, M., \& Slimane, K. B. (2017) Marketing to the (new) generations: Summary and perspectives. Journal of Strategic Marketing, 25, 179-189. doi: 10.1080/0965254X.2017.1291173.

[74] Hillman, D. R. (2014). Understanding multigenerational work-value conflict resolution. Journal of Workplace Behavioral Health, 29, 240-257. doi: 10.1080/15555240.2014.933961.

[75] Cogin, J. (2012). Are generational differences in work values fact or fiction? Multi-country evidence and implications. The International Journal of Human Resource Management, 23, 2268-2294. doi: 10.1080/09585192.2011.610967. 
[76] Ryan, R. M., \& Deci, E. L. (2000a). Intrinsic and extrinsic motivations: Classic definitions and new directions. Contemporary Educational Psychology, 25 (1), 54-67. doi: 10.1006/ceps.1999.1020.

[77] Ryan, R. M., \& Deci, E. L. (2000b). Self-determination theory and the facilitation of intrinsic motivation, social development, and well-being. American Psychologist, 55 (1), 68-78. doi: 10.1037/0003-066X.55.1.68.

[78] Lips-Wiersma, M., \& Morris, L. (2009). Discriminating between 'meaningful work' and the 'management of meaning.' Journal of Business Ethics, 88, 491-511. doi: 10.1007/s10551-009-0118-9.

[79] Bureau of Labor Statistics, U.S. Department of Labor (2018). Labor force statistics from the current population survey. Retrieved from https://www.bls.gov/cps/cpsaat07.htm

[80] Cochran, W. G. (1947) Some consequences when the assumptions for analysis of variance are not satisfied.
International Biometric Society, 3 (1), 22-38. doi: $0.2307 / 3001535$.

[81] Glass, G. V., Peckham, P. D., \& Sanders, J. R. (1972). Consequences of failure to meet assumptions underlying the fixed effects analyses of variance and covariance. Review of Educational Research, 42 (3), 237-288. doi: 10.3102/00346543042003237.

[82] Maxwell, S. E., \& Delaney, H. D. (2004). Designing experiments and analyzing data: A model comparison perspective (2nd ed.). NY: Psychology Press.

[83] Cohen, J. (1962). The statistical power of abnormal-social psychological research: A review. The Journal of Abnormal and Social Psychology, 65, 145-153. doi: 10.1037/h0045186.

[84] Micceri, T. (1989). The unicorn, the normal curve, and other improbable creatures. Psychological Bulletin, 105 (1), 156-166. doi: 10.1037/0033-2909.105.1.156. 